Boise State University

ScholarWorks

Chemistry Faculty Publications and Presentations

Department of Chemistry and Biochemistry

$12-1-2015$

\title{
Modification of Cellular DNA by Synthetic Aziridinomitosenes
}

\author{
Chris M. Mallory \\ Boise State University \\ Ryan P. Carfi \\ Boise State University \\ SangPhil Moon \\ Boise State University \\ Kenneth A. Cornell \\ Boise State University \\ Don L. Warner \\ Boise State University
}

\section{(c) $\oplus \Theta \Theta$}

This is an author-produced, peer-reviewed version of this article. (C) 2015, Elsevier. Licensed under the Creative Commons AttributionNonCommercial-NoDerivatives 4.0 International license. Details regarding the use of this work can be found at: https://creativecommons.org/ licenses/by-nc-nd/4.0/. The final, definitive version of this document can be found online at Bioorganic \& Medicinal Chemistry, doi: 10.1016/ j.bmc.2015.10.028 
Modification of cellular DNA by synthetic aziridinomitosenes

Chris M. Mallory

E-mail address: chrismmallory@gmail.com

Ryan P. Carfi

E-mail address: ryancarfi@u.boisestate.edu

SangPhil Moon

E-mail address: philmoon@u.boisestate.edu

Kenneth A. Cornell

E-mail address: kencornell@boisestate.edu

Don L. Warner*

E-mail address: dwarner@boisestate.edu

Department of Chemistry and Biochemistry, Boise State University, Boise, ID 83725, USA

*Corresponding author. Tel.: +1 208 426 3030; fax: +1 208426 3027. E-mail address: dwarner@boisestate.edu (D. Warner).

\section{Table of Contents Graphic}

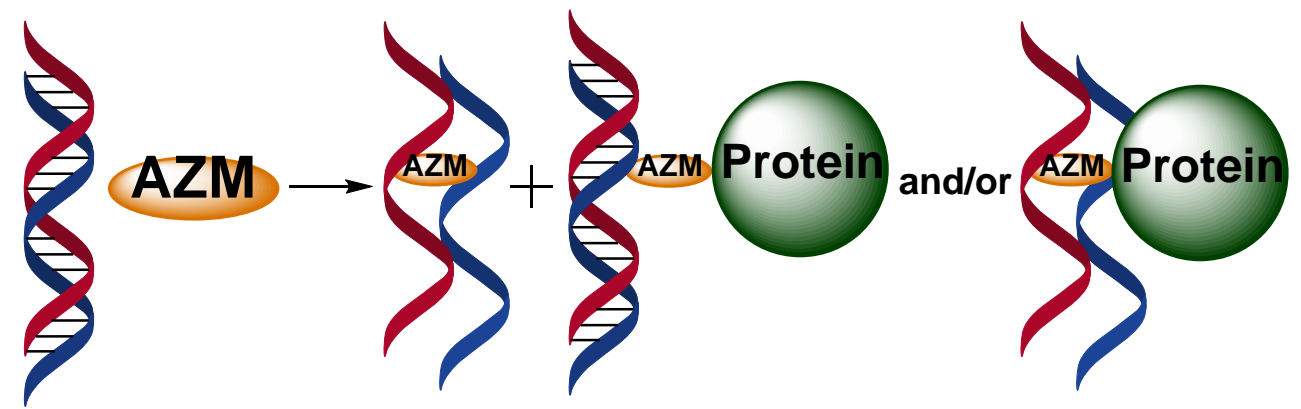

\section{$\underline{\text { Abstract }}$}

Two synthetic aziridinomitosenes (AZMs), Me-AZM and H-AZM, structurally related to mitomycin C (MC) were evaluated for their anticancer activity against six cancer cell lines (HeLa, Jurkat, T47D, HepG2, HL-60, and HuT-78) and tested for their DNA-modifying abilities in Jurkat cells. Cytotoxicity assays showed that MeAZM is up to 72-fold and 520-fold more potent than MC and H-AZM, respectively. Me-AZM also demonstrated increased DNA modification over MC and H-AZM in alkaline COMET and Hoechst fluorescence assays that measured crosslinks in cellular DNA. Me-AZM and H-AZM treatment of Jurkat cells was found to sponsor significant DNA-protein crosslinks using a K-SDS assay. The results clearly indicate that the AZM C6/C7 substitution pattern plays an important role in drug activity and supports both DNA-DNA and DNA-protein adduct formation as mechanisms for inducing cytotoxic effects.

\section{$\underline{\text { Keywords }}$}

Mitomycin C; aziridinomitosene; DNA adducts; alkylating agents

\section{Abbreviations}

Aziridinomitosene: AZM; mitomycin C: MC; DNA interstrand crosslink: ICL; aziridinomitosene-DNA-protein crosslink: DPC 


\section{Introduction}

DNA-modifying agents are an important and valuable class of drugs used in conventional chemotherapy. Mitomycin C (MC, see Figure 1), a natural product first isolated from the soil bacteria Streptomyces caespitosus, ${ }^{1}$ is a member of this class and has historically had a role in the treatment of a number of cancers, including colorectal, gastric, bladder, lung, head and neck, and non-small-cell lung cancers. ${ }^{2,3}$ MC requires intracellular activation by diaphorase, ${ }^{4}$ cytochrome P450 reductase, ${ }^{5}$ or other 1 - or 2-electron reductases, ${ }^{6}$ to form MC-leucoaziridinomitosene (Figure 1), the fate of which depends upon the activation conditions. Under conditions of fast $\mathrm{MC}$ reduction, low concentration, and acidic $\mathrm{pH}$, bifunctional activation of the MCleucoaziridinomitosene is favored, ${ }^{7}$ which exerts antitumor effects through creation of DNA interstrand crosslinks (ICLs) that prevent DNA replication and cause cell death. ${ }^{8,9}$ The sequence involves acid-catalyzed aziridine ring opening of the MC-leucoaziridinomitosene to form an initial leucoaziridinomitosene-DNA monoadduct. Ensuing carbamate departure and subsequent nucleophilic attack, followed by oxidation, results in the MC-DNA ICL structure.

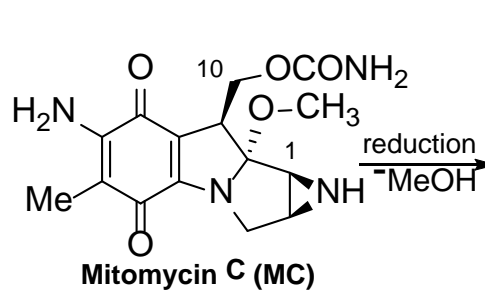

MC-leucoaziridinomitosene
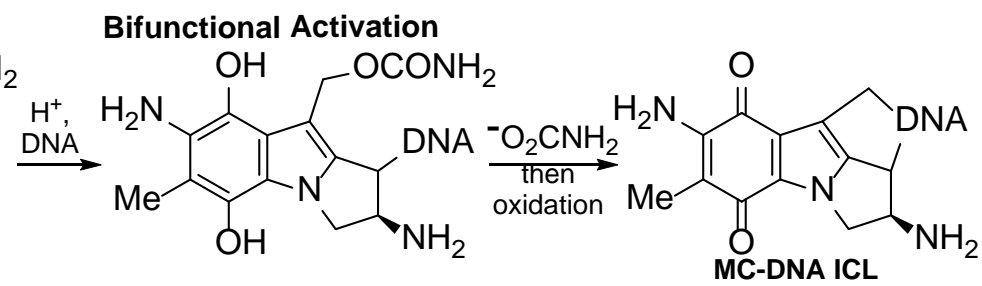

Monofunctional Activation

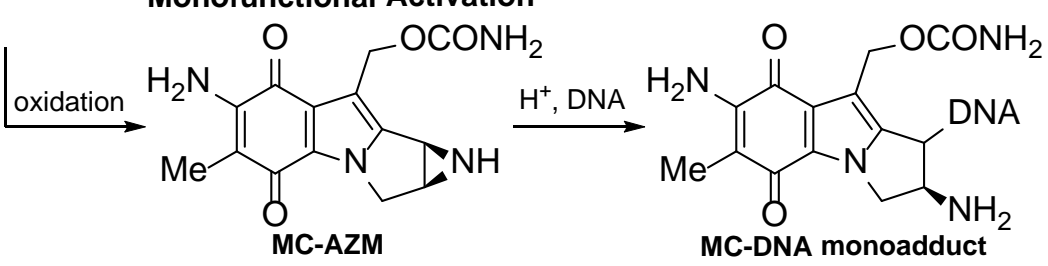

Figure 1. Mechanism for MC activation that results in DNA ICLs (via bifunctional activation pathway) and DNA monoadducts (via monofunctional activation pathway).

Under conditions of slow MC reduction, high drug concentration, or higher $\mathrm{pH}$, the hydroquinone moiety in the leucoaziridinomitosene re-oxidizes to yield the MC-AZM quinone structure that undergoes monofunctional activation (Figure 1). ${ }^{7,10,11} \mathbf{M C}-\mathbf{A Z M}$ is proposed to primarily cause DNA monoalkylation at C1 through acidactivation to produce a protonated aziridine that ring opens to relieve the strain associated with the threemembered ring. ${ }^{12}$ The presence of the adjacent electron deficient quinone moiety in the MC-DNA monoadduct disfavors expulsion of the C10 carbamate group that is necessary to create the ICL. Further, the location of the MC-DNA monoadduct within the DNA minor groove is thought to sterically hinder additional enzymatic reduction of the quinone ring, which is essential for carbamate departure. ${ }^{13-15}$

The mechanism of AZM-sponsored DNA monoalkylation is generally well accepted. However, in contrast to previous AZM studies, the synthetic C6/C7 unsubstituted (1S,2S)-6-desmethyl(methylaziridino)mitosene (HAZM, Figure 2) was shown to crosslink DNA in the absence of an exogenous reductant. ${ }^{16}$ Instead, H-AZM bisalkylated self-complementary DNA with the 5'-d(CG) dinucleotide sequence as the minimum common element. ICL production was optimal at $\mathrm{pH} 6$ and overall yield increased with reaction time (up to 48 hours). H-AZM treatment of duplex DNA containing the inverted 5'-d(GC) dinucleotide sequence resulted in no detectable ICL product. Similarly, H-AZM treatment failed to crosslink DNA sequences where the dG residues were replaced 
with 2'-deoxyinosines (dI) that lack the exocyclic C2 amino group in the purine ring. Thus, H-AZM appears to mediate dG-dG nucleobase ICL in the minor groove of the DNA duplex, but via an as yet unknown mechanism.

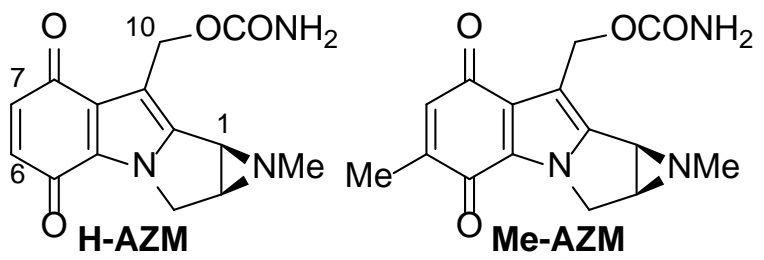

Figure 2. Structures of H-AZM and Me-AZM.

In a DNA footprinting/UvrABC nuclease assay used to examine H-AZM modification of a 129-base pair DNA fragment, the autoradiogram displayed bands corresponding to DNA adducts with molecular weights higher than the starting DNA fragment. ${ }^{17}$ Notably, one of the bands increased upon addition of the nuclease and, consequently, it was speculated that H-AZM was facilitating the formation of covalent DNA-protein crosslinks (DPCs). In the same experiments, an AZM derived from mitomycin A did not produce analogous adducts. Besides this tentative evidence, to the best of our knowledge, there are no other literature reports of AZMs forming DPCs. However, MC has been shown to facilitate the crosslinking of actin to DNA in human leukemia and myeloma cells. ${ }^{18-20}$

In this study, we evaluate the cellular toxicity of H-AZM and its C6 methyl derivative Me-AZM (Figure 2). ${ }^{17}$ Cytotoxicity was tested against a panel of six different human cancer cell lines ( 3 adherent and 3 non-adherent) using a resazurin reduction assay to evaluate cell viability and proliferation. Mechanistic studies were performed to evaluate AZM-induced DNA interactions. Me-AZM- and H-AZM-treated Jurkat cancer cells were analyzed by single cell gel electrophoresis (COMET), Hoechst 33342 staining, and K-SDS DNA-Protein crosslinking assays to assess the formation of DNA-DNA and DNA-protein adducts.

\section{Results/Discussion}

\subsection{Resazurin reduction assay and AZM stability}

The cytotoxic effects of Me-AZM, H-AZM, and MC against cancer cell cultures were determined using a resazurin reduction assay that follows the conversion of blue non-fluorescent resazurin to pink fluorescent resorufin that occurs in healthy metabolically active cells. ${ }^{20,21}$ The antiproliferative effects of Me-AZM, HAZM, and MC against six human cancer cell lines are summarized in Table 1 (see supplemental content for representative cytotoxicity profiles). All three compounds produced drug $\mathrm{IC}_{50}$ values that ranged from low nanomolar to low micromolar concentrations.

$\underline{\text { Table 1. Summary of drug antiproliferative effects. }}$

\begin{tabular}{|c|c|c|c|c|c|c|}
\hline \multirow{3}{*}{$\begin{array}{c}\text { Cell line } \\
\text { HeLa }\end{array}$} & \multirow[b]{2}{*}{ Type } & \multirow[b]{2}{*}{$\begin{array}{l}\text { Adherent/ } \\
\text { Suspension }\end{array}$} & \multicolumn{4}{|c|}{ Mean $\mathrm{IC}_{50}( \pm \mathrm{SEM})(\mathrm{nM})^{\mathrm{a}}$} \\
\hline & & & \multicolumn{2}{|r|}{$\mathrm{MC}$} & H-AZM & Me-AZM \\
\hline & Cervical Adenocarcinoma & Adherent & 1,870 & \pm 372 & $6,208 \pm 523$ & $525 \pm 242$ \\
\hline HepG2 & Hepatocellular Carcinoma & Adherent & 2,937 & \pm 209 & $7,870 \pm 701$ & $342 \pm 73$ \\
\hline T47D & Breast Ductal Carcinoma & Adherent & 16,970 & $\pm 1,472$ & $9,291 \pm 1,516$ & $225 \pm 78$ \\
\hline HL-60 & Acute Promyelocytic Leukemia & Suspension & 410 & 86 & $2,033 \pm 967$ & $30 \pm$ \\
\hline HuT-78 & Cutaneous T-Cell Lymphoma & Suspension & 66 & 33 & $131 \pm$ & $24 \pm 16$ \\
\hline Jurkat & T-Cell Leukemia & Suspension & 578 & 67 & $4,160 \pm 530$ & $8 \pm$ \\
\hline Jurkat & T-Cell Leukemia (hypoxic) & Suspension & 303 & \pm 131 & $3,965 \pm$ & $4 \pm$ \\
\hline
\end{tabular}

${ }^{\mathrm{a}} \mathrm{IC}_{50}$ values represent the mean $( \pm$ SEM) of three independent experiments (with at least $\mathrm{n}=3$ for each experiment). 
Me-AZM was at least 2.75 times more active than $\mathbf{M C}$ and at least 5.5 times more active than $\mathbf{H}$-AZM against every cell line. The difference was most notable in Jurkat cells, where Me-AZM was 72-fold more potent than MC and 520-fold more potent than H-AZM. Overall, the quinone-unsubstituted $\mathbf{H}$-AZM was the least toxic of the three compounds, with $\mathrm{IC}_{50}$ values that were typically 2- to 13-fold lower than those of MC, although it showed greater activity against T47D cells. Also, the three compounds were not as effective against adherent cancer cell lines, displaying activity that was in the low micromolar range for $\mathbf{M C}$ and $\mathbf{H}-\mathbf{A Z M}\left(\mathrm{IC}_{50}=2-17\right.$ $\mu \mathrm{M})$ and the sub-micromolar range for Me-AZM ( IC $\left._{50}=0.2-0.5 \mu \mathrm{M}\right)$.

The increased potency of Me-AZM over MC and H-AZM may be due to presence of the methyl group at C6, lack of a hydrophilic amine group at $\mathrm{C7}$, and methylation of the aziridine ring that may improve the electrophilic integrity of the AZM and stabilize the molecule for productive reactions with cellular nucleophiles. Alternatively, evidence suggests that $\mathbf{H}-\mathbf{A Z M}$ is inherently more reactive than other AZMs, especially under basic/nucleophilic conditions, and this may account for its decreased potency. For example, H-AZM was reported to decompose to unidentifiable products in basic methanol solutions in a manner that was consistent with 1,4-addition (i.e., Michael addition) of an oxygen nucleophile into the quinone ring. ${ }^{17}$ In analogous experiments, AZMs derived from MC underwent only aziridine ring-opening. ${ }^{12}$ However, H-AZM was more stable than the other tested compounds in neutral and mildly acidic methanolic solutions. ${ }^{17}$

To examine whether drug instability could explain the differences in drug IC50 results, the decomposition of Me-AZM and H-AZM in cell culture media (DMEM + 10\% FBS) was monitored via HPLC (see supplemental content). The results indicate that H-AZM decomposes rapidly in culture media, with only $10 \%$ of the compound remaining after 2 hours. In contrast, Me-AZM was more stable, with $90 \%$ of the compound remaining after 2 hours. Further, chromatograms suggest AZMs decompose to large molecular weight components that overlap with contents of the cell culture media. These results, taken together with the methanol solvolysis experiments, ${ }^{17}$ suggest that $\mathbf{H}$-AZM is more susceptible to base or nucleophile-mediated decomposition that most likely occurs via nucleophilic addition at C6 and/or C7. Bionucleophiles (e.g., amino acids, albumin, etc.) present in the cellular media probably sequester $\mathbf{H}$-AZM before it reaches a significant cellular target, thus mitigating its overall cytotoxicity.

Although Me-AZM was consistently more potent than MC, the resazurin reduction assays were conducted under aerobic conditions. Given MC's requirement for reductive activation and reported increased efficacy against hypoxic cells, ${ }^{23}$ we evaluated the antiproliferative effects of Me-AZM, H-AZM, and MC against Jurkat T-cell leukemia cells that were first incubated in a $95 \% \mathrm{~N}_{2} / 5 \% \mathrm{CO}_{2}$ environment and then in a hypoxic chamber for the duration of the experiment. Under these conditions, a slight but statistically insignificant increase in potency was observed for each compound. However, Me-AZM remained the most effective, with an $\mathrm{IC}_{50}$ that was approximately 75-fold more potent than $\mathbf{M C}$, suggesting that Me-AZM is more cytotoxic than MC regardless of the oxygen tension in the experiment.

\subsection{Modified alkaline single cell gel electrophoresis (COMET) assay}

A modified COMET assay was used to assess the ability of synthetic AZMs to form DNA crosslinks. ${ }^{24-27}$ The assay investigates the extent of drug-induced DNA crosslinking in individual cells by visualizing and quantifying DNA migration following exposure to DNA damaging agents. ${ }^{25}$ The study examined the electrophoretic mobility of DNA from individual cells first treated with MC, Me-AZM, or H-AZM and then subsequently treated with hydrogen peroxide. The hydrogen peroxide induces DNA strand breaks, which increases the DNA's electrophoretic mobility and results in the appearance of an elongated "tail” in the electropherogram. Agents that sponsor DNA crosslinks prior to hydrogen peroxide exposure hinder migration 
during electrophoresis due to increased DNA fragment size or alterations to DNA contour during migration through agarose. This leads to a decreased tail length when compared to cells treated with hydrogen peroxide alone. ${ }^{24,27}$ A smaller value for the "tail extent moment", which is calculated by multiplying tail length by the measured amount of DNA in the tail, ${ }^{24,25}$ is indicative of increased DNA interstrand, intrastrand, or DNAprotein crosslinks.
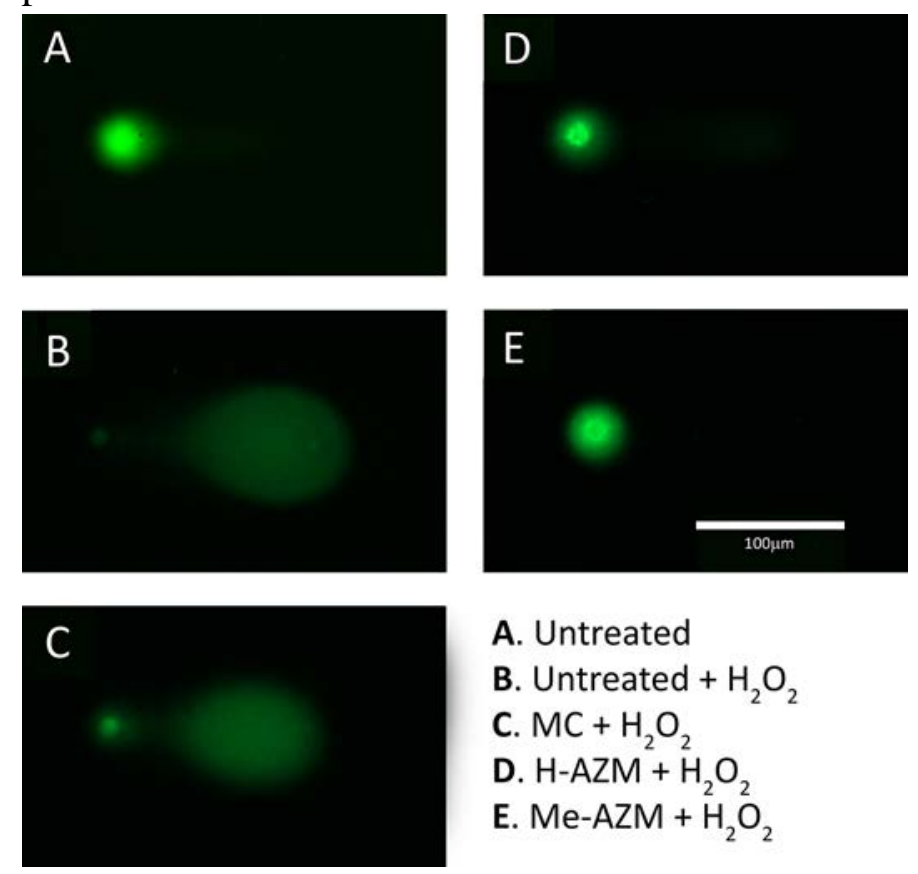
A. Untreated
B. Untreated $+\mathrm{H}_{2} \mathrm{O}_{2}$
C. $\mathrm{MC}+\mathrm{H}_{2} \mathrm{O}_{2}$
D. $\mathrm{H}-\mathrm{AZM}+\mathrm{H}_{2} \mathrm{O}_{2}$
E. $\mathrm{Me}-\mathrm{AZM}+\mathrm{H}_{2} \mathrm{O}_{2}$

Figure 3. Representative fluorescent images of aerobic Jurkat cells following the modified alkaline COMET assay and SYBR green staining. (A) Drug untreated cells: minimal DNA strand breaks control; (B) Drug untreated cells $+\mathrm{H}_{2} \mathrm{O}_{2}$ : maximal DNA strand breaks control; (C-E) MC, H-AZM, Me-AZM treated cells $+\mathrm{H}_{2} \mathrm{O}_{2}$. Homologous images for COMET assays performed under hypoxic conditions can be found in supplemental content.

The COMET assay electropherograms show that $10 \mu \mathrm{M}$ AZM treatment results in decreased DNA mobility from peroxide induced strand breaks alone (Figure 3). In Jurkat cells under aerobic conditions, both AZMs produced significant reductions in tail extent moments relative to the $100 \mu \mathrm{M} \mathrm{H}_{2} \mathrm{O}_{2}$ treatment control. MeAZM and He-AZM treatment produced similar mean tail extent moments $(0.26 \pm 0.4$ and $0.49 \pm 0.07$, respectively), indicating that extensive DNA crosslinks had occurred (Figure 4). Under the same conditions, MC produced a tail extent moment $(96.0 \pm 6.0)$ that was not statistically different from the $100 \mu \mathrm{M} \mathrm{H}_{2} \mathrm{O}_{2}$ treatment control, indicating minimal DNA crosslinks. Under hypoxic conditions, Me-AZM and H-AZM treatment continued to cause extensive DNA crosslinks (tail extent moments of $0.32 \pm 0.29$ and 3.6 \pm 0.7 , respectively). However, MC treatment under hypoxic conditions resulted in a slight, but statistically significant decrease in tail extent moment $(87.0 \pm 2.5)$. This result is consistent with literature reports indicating that the extent of crosslinks detected by the COMET is highly dependent upon cell type and drug incubation time, ${ }^{28}$ and high drug concentrations are often required to visualize substantial responses. ${ }^{24,25}$ 


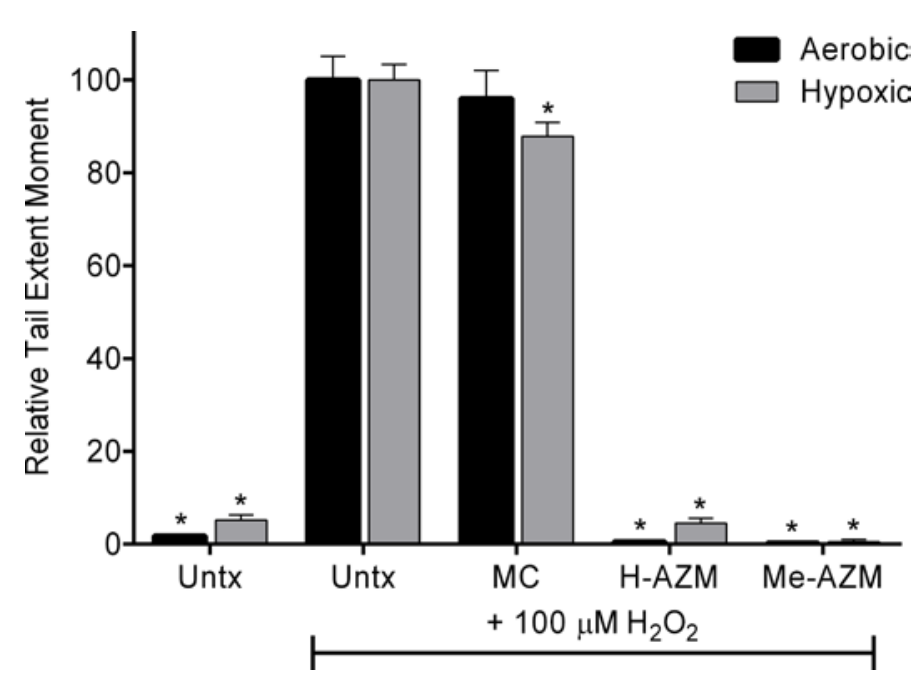

Figure 4. Modified alkaline COMET assay of Jurkat cells. Tail extent moments are expressed as the mean \pm SEM of two experiments ( $\mathrm{n}>50$ cells per treatment). * denotes $\rho<0.05$ by two-way ANOVA, when compared to the matched (i.e., aerobic or hypoxic) peroxide treatment control (Untx $\left.+100 \mu \mathrm{M} \mathrm{H}_{2} \mathrm{O}_{2}\right)$. (Untx = no drug treatment, $\mathbf{M C}=$ mitomycin $\mathrm{C}$ treated cells, $\mathbf{H}-\mathbf{A Z M}$ and $\mathbf{M e}-$ $\mathbf{A Z M}=$ aziridinomitosene treated cells.)

\subsection{Hoechst 33342 fluorescence assay}

Prior investigations of DNA crosslinkage by synthetic AZMs were confined to demonstrations of adduct formation with purified nucleic acids or oligonucleotides. The COMET assays described above do not differentiate between DNA interstrand, intrastrand, or DNA-protein crosslinks. To further establish that AZMs could form DNA ICLs in eukaryotic cellular environments, we evaluated DNA modification induced by MeAZM and H-AZM in Jurkat cell lines using a Hoechst 33342 fluorescence assay. ${ }^{29-31}$ When bound to double stranded DNA (dsDNA), Hoechst dyes exhibit increased fluorescence compared to single stranded DNA (ssDNA). The premise of the assay is that DNA crosslinks lead to increased retention of fluorescent Hoechst dye compared to un-crosslinked DNA. Thermal denaturation followed by rapid cooling normally causes DNA base pair mismatches that yield extensive regions of ssDNA with decreased Hoechst fluorescence. Covalent DNA crosslinks act as anchor points, decreasing the level of base pair mismatches that occur following a series of heat denaturation/rapid cooling processes. Thus, more heavily crosslinked DNA will exhibit increased recovery of dsDNA character and retention of Hoechst fluorescence. ${ }^{29}$

In this study, Me-AZM treatment of Jurkat cells produced a significant increase in the amount of crosslinked DNA when compared to similar treatment with MC or H-AZM (Figure 5). The amount of Me-AZM sponsored crosslinks per DNA fragment was calculated at $0.55 \pm 0.05$ and $0.51 \pm 0.02$ for aerobic and hypoxic cells, respectively. These values are 68-fold and 8-fold greater than the crosslinks per DNA fragment sponsored by MC treatment. Consistent with our earlier observations, the effects of H-AZM treatment were more modest, showing a 13-fold increased amount of crosslinked DNA relative to MC under aerobic conditions. Under hypoxic conditions, H-AZM treatment did not produce a significant increase in crosslinked DNA relative to MC treatment. 


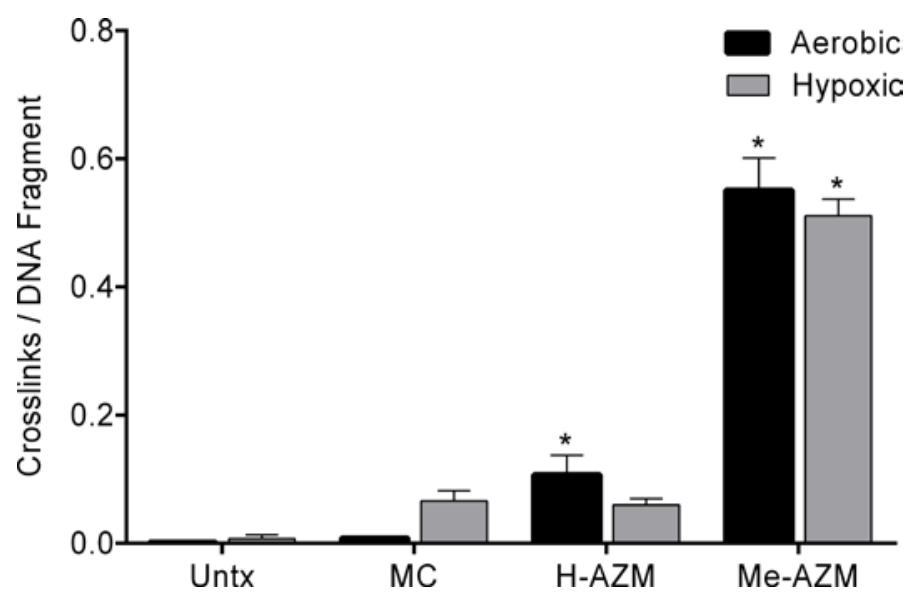

Figure 5. DNA-DNA crosslinks in AZM and MC treated Jurkat cell lines. Cellular DNA was isolated after treatment with $10 \mu \mathrm{M}$ MC, H-AZM, or Me-AZM, the crosslinks per DNA fragment were measured as a decrease in Hoechst 33342 - DNA fluorescence relative to untreated cellular DNA. Data presented is the mean \pm SEM of two experiments $(n=6)$. $*$ denotes $\rho<0.05$ by two-way ANOVA when compared to the matched (i.e., aerobic or hypoxic) untreated control.

The Hoechst 33342 fluorescence assay results showed that Me-AZM and H-AZM treatment produced DNA crosslinks in cells after one hour of treatment under aerobic conditions, whereas only Me-AZM crosslinked DNA to a significant extent in an hypoxic environment. MC treatment under aerobic and anaerobic conditions produced minimal DNA modification. These results are consistent with our earlier findings demonstrating that Me-AZM is the most active DNA-modifying agent of the three compounds, and that hypoxia only minimally alters the experimental outcome. Further, AZM-induced DNA ICL formation is consistent with previous reports that demonstrated H-AZM treatment of purified DNA and oligonucleotides under non-reductive conditions resulted in DNA-DNA crosslinks. ${ }^{16,17}$

For H-AZM, there is an apparent discrepancy between the COMET and Hoechst assays in that one shows extensive DNA crosslinkage while the other does not. However, proteins are removed during the DNA isolation process required for the Hoechst assay, which probably removes DNA containing DPCs from the isolated DNA. With the COMET assay, the entire cell is examined under electrophoresis, so this experiment does not distinguish between DNA ICLs or DPCs. Thus, if the majority of H-AZM produces DPCs, a reduced tail moment on the COMET assay would be observed, but DNA crosslinks would be minimized in the Hoechst assay.

\subsection{K-SDS DNA-protein crosslinking assay}

The K-SDS assay has been widely used to study drug sponsored DNA-protein crosslinks (DPCs). Previous studies, employing the alkaline elution assay, have shown that MC induces DPCs in mammalian cells, ${ }^{18-20,32}$ but no reports have demonstrated that AZMs induce DPCs in vitro. To determine the potential of AZMs to crosslink DNA to protein we used an adaptation of the K-SDS assay first described by Zhitkovitch and Costa. ${ }^{33}$ Unlike the alkaline elution assay, the K-SDS assay conditions cause disassociation of non-covalently bound DNA, and selective salt precipitation of DNA-protein adducts to effectively allow separation and quantification of covalent DNA-protein complexes. 


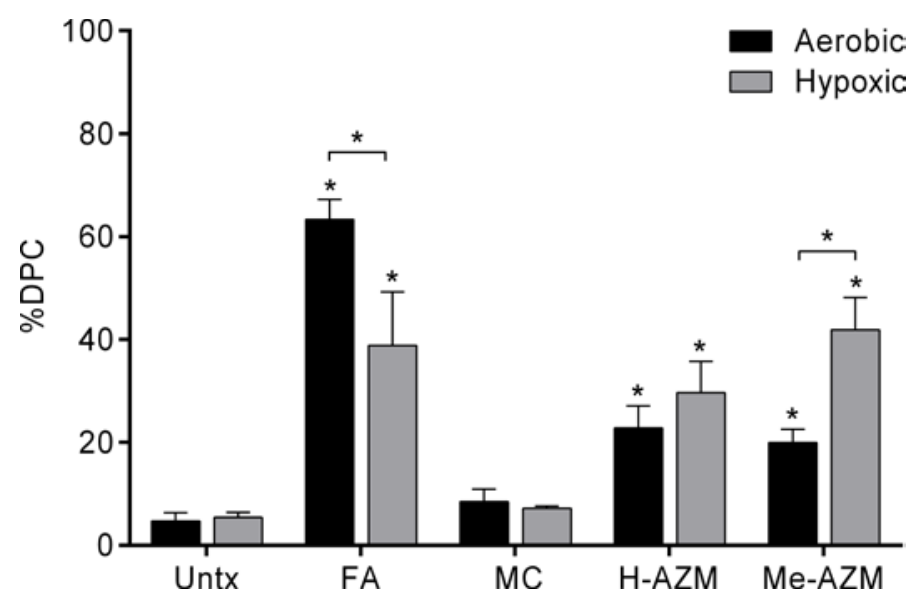

Figure 6. K-SDS assay for DPCs in drug treated Jurkat cells. DPCs were isolated from Jurkat cells after 1.5 h treatment with saline (Untx), $3 \mathrm{mM}$ formaldehyde (FA,) or $100 \mu \mathrm{M}$ concentrations of MC, H-AZM, or Me-AZM. Data is presented as the mean \pm SEM of three independent experiments $(\mathrm{n}=9)$. * denotes $\rho<0.05$ by two-way ANOVA when compared to the matched aerobic or hypoxic untreated control (no bracket) or when compared to reaction conditions for a given treatment (with bracket).

The K-SDS assay conducted under aerobic conditions demonstrated that $100 \mu \mathrm{M}$ Me-AZM and H-AZM treatment induced significant increases in DPCs (17-20\%) relative to the untreated Jurkat cell control (Figure 6). Treatment with $3 \mathrm{mM}$ formaldehyde (FA), a known DNA-protein crosslinking agent, showed the highest \% DPC (53.2 $\pm 3.7 \%)$. Cells treated with $100 \mu \mathrm{M}$ MC did not show significant increases in DPC (7.8 $\pm 2.3 \%)$ formation relative to the untreated control $(4.5 \pm 1.5 \%)$, indicating these are not the primary DNA modifications sponsored by MC. Interestingly, DPC formation for Me-AZM (41.9 $\pm 5.7 \%$ ) was enhanced under hypoxia. However, hypoxic conditions failed to significantly improve H-AZM and MC stimulated DPC, which remained statistically equivalent to untreated control.

Previous DNA footprinting studies with H-AZM resulted in high molecular weight, low mobility bands that were consistent with DPC formation during nuclease exposure in the assay. ${ }^{17}$ Since the K-SDS assay is specific for detecting chemically induced DNA-protein adducts, our current results with Me-AZM and H-AZM provide the first substantive evidence of an AZM sponsored DPC. The lack of significant DPC formation by MC contradicts prior studies that report MC stimulated actin crosslinks to DNA. ${ }^{18}$ This may be due to the increased specificity of this particular technique. The K-SDS assay was created for the sole purpose of detecting and isolating DPCs produced by crosslinking agents in vivo, ${ }^{33}$ and is thought to be more stringent than the alkaline elution method used in the previous study. ${ }^{18}$

In spite of its utility, the K-SDS assay does not discriminate between protein covalently bound to monoalkylated DNA or crosslinked DNA. Additionally, the order of binding events is not readily apparent after conclusion of the experiment. Additional experiments will be necessary to obtain these mechanistic details.

\subsection{Potential mechanisms for AZM ICL and DPC formation}

While the mechanism of DNA ICL and DPC formation by Me-AZM and H-AZM is currently unknown, we envision two reasonable mechanisms that could account for their formation in tumor cells and in reactions with DNA in the absence of reductant (Figure 7). The first, Path A, involves acidic activation of the C1 and C10 electrophilic sites. Rapid acid-catalyzed aziridine ring-opening results in a carbocation that is captured by nucleophilic DNA in the minor groove. Next, slow carbamate departure forms an iminium intermediate that undergoes a second nucleophilic addition to produce the ICL. The acidic activation mechanism is consistent with previous studies demonstrating that H-AZM forms DNA ICLs best under acidic conditions (pH 6) with long reaction times (up to 48 hours). ${ }^{16}$ Also, the acidic mechanism serves to rationalize the increased potency 
and increased DNA-binding efficiency of Me-AZM in cellular systems, reported herein, since incorporation of the electron donating methyl group should help stabilize the carbocations formed upon aziridine ring-opening and carbamate departure. However, the mechanism is inconsistent with several important observations. First, numerous AZMs with varying electronic properties have been reported in the literature, many of which are more electron rich than $\mathbf{H}-\mathbf{A Z M},{ }^{12}$ and it seems that acidic activation to yield DNA ICLs should have been observed with some of these AZMs. Second, the mechanism proposed in path A does not provide an obvious route to account for the previously unobserved DPCs. Finally, we have evidence (unreported) that H-AZM crosslinks synthetic DNA more efficiently than Me-AZM, ${ }^{34}$ which contradicts the proposed mechanism.

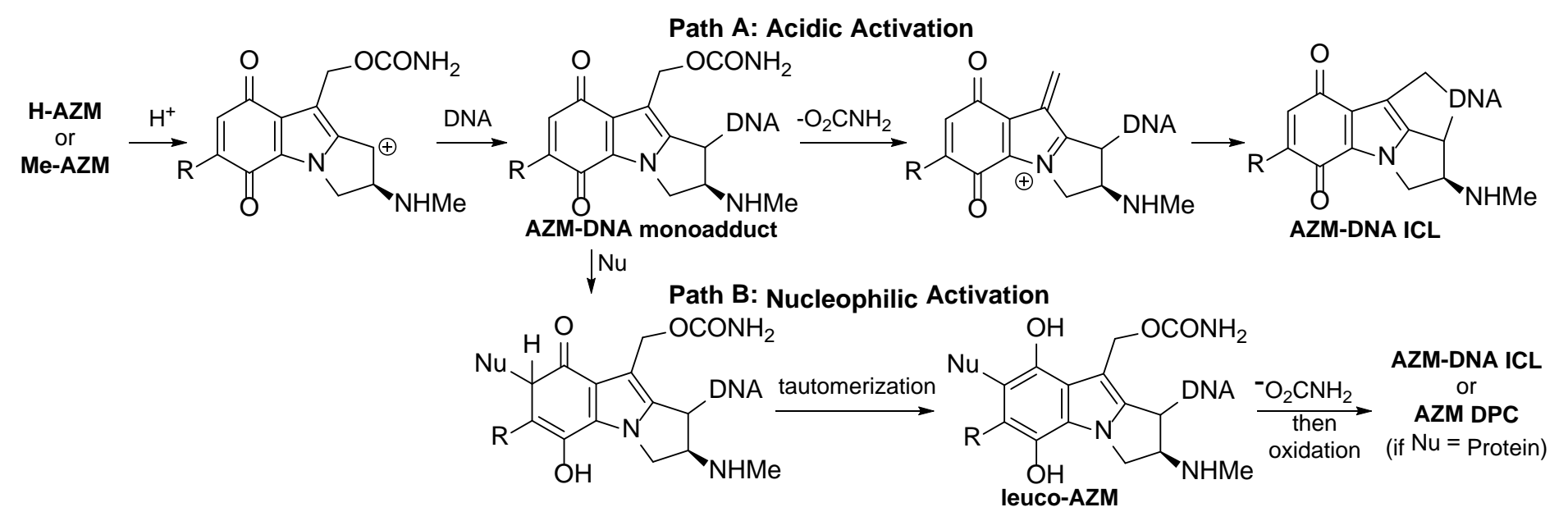

Figure 7. Potential mechanisms for the AZM-induced formation of DNA ICLs and DPCs in absence of reductant. Two reasonable mechanisms for the formation of DNA ICLs and DPCs include aziridine opening and carbamate departure via acidic activation (Path A, top) and carbamate departure via nucleophilic activation (Path B, bottom). Enzymatic reduction (not shown) in a manner analogous to MC may be occurring in cellular systems, but this does not explain the formation of adducts in absence of reductant.

The nucleophilic activation mechanism (Figure 7, Path B) has the notable feature of agreeing with prior reports indicating that carbamate departure and subsequent ICL formation requires either extreme acidic conditions (pH $<5)^{35}$ or reductive activation. ${ }^{10}$ Also, the mechanism agrees with our own observations to a greater extent and invokes the lack of quinone substitution, a key structural feature that is unique to these particular AZMs. In both compounds, at least one of the quinone carbon atoms is unsubstituted, which renders the AZMs susceptible to Michael addition at that position. Given this, the first step in the hypothesized mechanism involves the standard acid catalyzed aziridine ring-opening and DNA monoadduct formation, typical of previously reported AZMs. Next, Michael addition by media or a cellular nucleophile results in an intermediate that can tautomerize to a leucoaziridinomitosene species (leuco-AZM) where carbamate expulsion and crosslink formation are favored. Support for this mechanism is provided by the non-enzymatic activation of mitomycin A by thiols, which has been proposed to follow a sequence that is initiated by nucleophilic attack at C7. ${ }^{36,37}$

Nucleophilic activation also provides a potential avenue for DPC formation, if the nucleophile facilitating activation is a DNA-associated protein. Further, Michael addition into the quinone ring offers an explanation for the decreased potency of H-AZM compared to Me-AZM. Structurally, H-AZM affords two quinone electrophilic sites, since both C6 and C7 are unsubstituted. In contrast, Me-AZM presents only C7 as an electrophilic center. Thus, $\mathbf{H}$-AZM is expected to be a highly reactive Michael acceptor that is more prone to nucleophilic sequestration by cell media or other bionucleophiles prior to DNA alkylation. Our HPLC decomposition experiments support the increased sensitivity to nucleophiles, as the DMEM cell culture media resulted in about 90\% decomposition of H-AZM in about 2 hours, whereas Me-AZM resulted in only about $10 \%$ decomposition over the same period of time. Thus, the formation of ICLs and DPCs by both AZMs, along 
with the rapid decomposition of $\mathbf{H - A Z M}$, are indicative of Path B as the more likely mechanism for DNA adduct formation in absence of reductant.

\section{Conclusion}

Two synthetic AZMs, differing only by the presence or absence of a quinone ring methyl at C6, were examined for their ability to modify human cellular DNA. While both Me-AZM and H-AZM demonstrated DNA modification, Me-AZM exerted more potent antiproliferative effects against cancer cell lines that were consistently better than the effects of MC. The results of the modified COMET assays, Hoechst fluorescence, and K-SDS assays suggest that the antiproliferative effects could in part be attributed to drug sponsored DNA damage that yield either ICLs and/or DPCs. It is noteworthy that Me-AZM treatment produced much stronger antiproliferative effects and more DNA adducts than H-AZM. Potentially, H-AZM showed lesser effects because the unsubstituted quinone ring is a more reactive target for nucleophilic addition, which renders it more prone to decomposition and decreased half-life in the cellular environment or extracellular media. The methyl group at C6 in Me-AZM may sterically hinder nucleophile accessibility to the quinone ring, thus improving the half-life of the AZM by preventing non-productive reactions with other biomolecules outside the context of the DNA. Future experiments will be directed towards determining the DNA alkylating abilities of additional AZM analogs with chemical modification at the C6 and C7 positions, characterizing the DNA-AZM adducts that are produced in reactions with DNA and DNA-associated proteins in both cell cultures and in cell-free environments, and evaluating the role of quinone reduction in DNA crosslinking experiments.

\section{Materials and Methods}

\subsection{Materials}

Me-AZM and H-AZM were synthesized in our laboratory according to previously reported methods. ${ }^{17,38}$ MC was purchased from Cayman Chemical (Ann Arbor, MI). Resazurin sodium salt was acquired from Acros Organics (Fairlawn, New Jersey). Anhydrous dimethyl sulfoxide (DMSO) was obtained from Sigma (St. Louis, MO). Hoechst 33342 and 10,000x SYBR Green were obtained from Invitrogen (Carlsbad, CA). HyClone growth media (RPMI-1640 and Dulbecco's Modified Eagles Medium (DMEM) and penicillin/streptomycin were obtained from Thermo Scientific (Waltham, MA). Fetal Bovine Serum (FBS) was purchased from Fisher Scientific (Hampton, NH). Ultracleen Tissue \& Cells DNA Isolation Kit was obtained from Mo Bio Laboratories Inc. (Carlsbad, CA). Proteinase K was purchased from AMRESCO (Solon, OH). The COMET Assay Kit was purchased from Trevigen (Gaithersburg, MD).

\subsection{Cell culture methods and drug stocks}

Aerobic Conditions: Six different human cell lines were used to evaluate the potency of the AZMs and MC. The three suspension (Jurkat, HUT-78, HL-60) and three adherent cancer cell lines (HeLa, T47D, HepG2) were the generous gifts from Drs. Denise Wingett, Cheryl Jorcyk and Kristen Mitchell, all from Boise State University. The Jurkat and T47D cells were cultured in RPM1-1640 supplemented with 10\% fetal bovine serum (FBS), penicillin (100 U/mL) and streptomycin $(100 \mu \mathrm{g} / \mathrm{mL})$ (pen/strep). HeLa and HepG2 cell lines were grown in Dulbecco's Modified Eagles Medium (DMEM) containing 10\% FBS with pen/strep. HL-60 and HUT78 cell lines were cultured in Iscove’s Modified Dulbecco's Medium (IMDM) supplemented with 20\% FBS and pen/strep. All cell lines were grown at $37^{\circ} \mathrm{C}$ in $5 \% \mathrm{CO}_{2}$. Stock solutions of Me-AZM, H-AZM, and MC were prepared in DMSO and stored at $-80^{\circ} \mathrm{C}$ prior to use. The stock solutions were thawed, quickly diluted in sterile nanopure water or $1 \mathrm{x}$ PBS to achieve working concentrations for experiments, and rapidly added to cells in order to minimize decomposition prior to AZM delivery. 
Hypoxic Conditions: To induce hypoxia, a method previously described by Wang et al. with minor modifications was used. ${ }^{39}$ The appropriate number of cells were transferred to well-ventilated flat bottom T-25 culture flasks in a MIC-101 Modular Incubator Chamber (Billups-Rothberg, Inc., Del Mar, CA) that was continuously purged with $95 \% \mathrm{~N}_{2} / 5 \% \mathrm{CO}_{2}$ for 15 min to effect complete gas exchange. The chamber was sealed and the cells incubated for an additional hour at $37^{\circ} \mathrm{C}$. PBS used for Me-AZM, H-AZM, and MC drug dilutions was sparged with $95 \% \mathrm{~N}_{2} / 5 \% \mathrm{CO}_{2}$ prior to addition of the appropriate compound. The AZMs and $\mathbf{M C}$ were delivered to the cells by quickly breaking the seal of the anaerobic chamber and pipetting directly into the flasks. The anaerobic chamber was resealed and purged for another 15 min with the $95 \% \mathrm{~N}_{2} / 5 \% \mathrm{CO}_{2}$ gas mixture. The cells were incubated in the sealed anaerobic chamber at $37^{\circ} \mathrm{C}$ for the time required for each given experiment.

\subsection{Resazurin reduction assay}

Adherent cells were harvested at high confluency during log phase of growth. Briefly, cells were washed with sterile PBS and trypsinized for $5 \mathrm{~min}$. Cells were collected by centrifugation (150-250 xg /5 min) and resuspended in the appropriate medium supplemented with FBS and 1\% penicillin/streptomycin. Sterile 96-well plates were seeded with 8,000 cells/well and then incubated for $24 \mathrm{~h}$ at $37{ }^{\circ} \mathrm{C}$ in $5 \% \mathrm{CO}_{2}$. The media was removed and replaced with fresh media containing dilutions of Me-AZM, H-AZM, MC, or vehicle to achieve the desired concentration gradient. Suspension cell lines were also plated at 8,000 cells/well. After drug addition, cells were incubated for an added $48 \mathrm{~h}$, at which time $20 \mu \mathrm{L}$ of $0.1 \%$ resazurin in sterile PBS was added into each well and incubated for an additional $4-24 \mathrm{~h}$ at $37^{\circ} \mathrm{C}$ in $5 \% \mathrm{CO}_{2}$. Fluorescence values (excitation/emission: 530/590 nm) were then obtained using a BioTek Synergy HT plate reader (BioTek, Winooski, VT). Fluorescence data was plotted as a percentage of the untreated value using GraphPad Prism and fit to a non-linear regression with $\log$ (inhibitor) vs. response for determination of IC $_{50}$ values. Data are presented as the mean $( \pm$ SEM) for at least three independent experiments with at least three replicate wells used in each experiment.

\subsection{Decomposition of Me-AZM and H-AZM in DMEM cell culture media}

HPLC analysis was conducted using an Agilent 100 series HPLC equipped with a $50 \mathrm{~mm}$ x $4.6 \mathrm{~mm}$ with $5 \mu \mathrm{m}$ pore size hypersil GOLD phenyl column and detected at 254 and $480 \mathrm{~nm}$. HPLC samples were prepared as quickly as possible (ca. $<5 \mathrm{~min}$ ) to minimize decomposition by adding Me-AZM and H-AZM stock solutions in DMSO to filter-sterilized DMEM containing 10\% FBS with pen/strep to yield a final concentration of 250 $\mu \mathrm{M}$ for Me-AZM and $250 \mu \mathrm{M}$ for H-AZM. The solutions were vortexed, filtered into HPLC vials using 0.2 $\mu \mathrm{M}$ pore size PTFE syringe filters. The vials were placed in an auto-sampler and $20 \mu \mathrm{L}$ of solution was injected into the HPLC every 15 min until near complete decomposition was observed. HPLC-grade acetonitrile $\mathrm{pH} 7.2$ Tris buffer were prepared as a mobile phase A and B, respectively. Gradients were conducted flow rate at 1.0 $\mathrm{ml} / \mathrm{min}$ for 15 minutes with the following linear program: $\mathrm{t}=0 \mathrm{~min}$ (30\%; A, 70\%; B), $\mathrm{t}=10 \mathrm{~min}(70 \%$;, $30 \%$; B), $t=12 \min (70 \%$; A, 30\%; B), $t=12.1 \mathrm{~min}(30 \% ; \mathrm{A}, 70 \%$; $)$, and $\mathrm{t}=15 \mathrm{~min}(30 \% ; \mathrm{A}, 70 \%$; $\mathrm{B}$. The HPLC retention times for H-AZM and Me-AZM were $2.9 \mathrm{~min}$ and $6.6 \mathrm{~min}$, respectively. Chromatograms are included in the supplemental content.

\subsection{Modified alkaline single cell gel electrophoresis (COMET) assay}

The alkaline COMET Assay was performed according to the manufacturer's protocol (Trevigen, Gaithersburg, MD) with minor modifications. Briefly, Jurkat cells were harvested, washed once with complete RPMI-1640, and reconstituted to a final density of $1 \times 10^{5}$ cells $/ \mathrm{mL}$. Cells were then either treated with a final concentration 
of either $10 \mu \mathrm{M}$ Me-AZM, H-AZM, MC, or $1 \mathrm{x}$ PBS for one hour at $37^{\circ} \mathrm{C}$ in $5 \% \mathrm{CO}_{2}$ with agitation every 15 min. After one hour, the cells were harvested by centrifugation, washed once in $1 \mathrm{x}$ PBS, then resuspended in $100 \mu \mathrm{M}$ hydrogen peroxide in $1 \mathrm{x}$ PBS for 20 minutes at $4{ }^{\circ} \mathrm{C}$. After treatment, cells were harvested by centrifugation at $4{ }^{\circ} \mathrm{C}(5 \mathrm{~min}, 150 \mathrm{xg}$ ), washed twice, and resuspended in $1 \mathrm{~mL}$ of $1 \mathrm{x}$ PBS. A $50 \mu \mathrm{L}$ portion of the cell suspension was combined with $500 \mu \mathrm{L}$ of $37^{\circ} \mathrm{C}$ low melting point agarose, and a $50 \mu \mathrm{L}$ portion spread evenly on the COMET slide. COMET slides were then allowed to solidify at $4{ }^{\circ} \mathrm{C}$ for 30 minutes in the dark, and then were submerged in lysis solution overnight at $4{ }^{\circ} \mathrm{C}$ in the dark. Next, the slides were submerged in a freshly prepared alkaline DNA unwinding solution $(\mathrm{pH}>13)$ for $20 \mathrm{~min}$ at $22{ }^{\circ} \mathrm{C}$ in the dark, and then subjected to electrophoresis (20V, $\sim 300 \mathrm{~mA}$ ) for $30 \mathrm{~min}$ at $4{ }^{\circ} \mathrm{C}$ under minimal light conditions. The slides were submerged in DI water twice (5 min), once ( $5 \mathrm{~min}$ ) with $70 \%$ ethanol, dried at $37{ }^{\circ} \mathrm{C}$ for $15 \mathrm{~min}$, and then stained with 1x SYBR Green solution in $10 \mathrm{mM}$ Tris, $1 \mathrm{mM}$ EDTA (pH 8.0) for 30 minutes at $22^{\circ} \mathrm{C}$ in the dark. Slides were then submerged into DI water to remove excess SYBR green and dried for $1-2$ hours at $37^{\circ} \mathrm{C}$. COMET slides were examined and images captured on an AMG Evos fluorescence microscope (Mill Creek, WA) using the 10x objective and GFP filter. Analysis for tail extent moment was performed using the OpenComet plugin for ImageJ $(\mathrm{NIH}),{ }^{40,41}$ and tail extent moments (mean \pm SEM) plotted in GraphPad Prism using a minimum of 50 COMET analyses per drug treatment group from two experiments.

\subsection{Hoechst 33342 fluorescence assay}

The Hoechst fluorescence assay was adapted from a previously reported DNA crosslinking assay. ${ }^{29}$ Jurkat cells ( $\sim-6$ x $10^{6}$ cells) were treated with either $10 \mu$ M MC, Me-AZM, H-AZM or 1x PBS for 1 hour. DNA from was then isolated using the Mo Bio Ultracleen Tissue \& Cells DNA Isolation Kit according to the manufacturer's instructions. Samples for the assay were prepared in the dark by combining isolated cellular DNA (3,750 ng) with $300 \mu \mathrm{L}$ of $1.0 \mu \mathrm{g} / \mathrm{mL}$ Hoechst 33342 dye in nanopure $\mathrm{H}_{2} \mathrm{O}$. The total volume was brought to $3 \mathrm{~mL}$ with $0.5 \mathrm{x}$ TE buffer. Sample fluorescence was measured using an excitation/emission wavelength of 360/460 nm. A fluorescence control reaction consisted of $3 \mathrm{~mL} \mathrm{0.5x} \mathrm{TE} \mathrm{buffer} \mathrm{containing} \mathrm{only} 0.1 \mu \mathrm{g} / \mathrm{mL}$ Hoechst 33342 dye. The retention of fluorescence was then measured after subjecting samples to a heat/chill process as follows: $5 \mathrm{~min}$ in a $96-98^{\circ} \mathrm{C}$ water bath, immediate chilling in an ice-water bath for 5 min, followed by incubation in a room temperature water bath for $5 \mathrm{~min}$. The fluorescence measurement was repeated and the crosslinked fraction determined using Equation 1:

$$
\begin{array}{ll}
\text { Cross-linked fraction }= & \frac{\frac{E_{A}}{E_{B}}-\frac{C_{A}}{C_{B}}}{1-\frac{C_{A}}{C_{B}}} \quad \text { Equation } 1
\end{array}
$$

Where, $C_{A}=$ fluorescence of control sample after heat/chill, $C_{B}=$ fluorescence of control sample before heat chill, $E_{A}=$ fluorescence of experimental sample after heat/chill, and $E_{B}=$ fluorescence of experimental sample before heat/chill.

Crosslinked fraction values were converted to crosslinks per DNA fragment using Equation 2:

$$
\text { Crosslinks per DNA fragment }=-\ln (1-\mathrm{X}) \quad \text { Equation } 2
$$


Where $\mathrm{X}=$ the crosslinked fraction, as determined using Equation 1.

Data was analyzed in Microsoft Excel and GraphPad Prism. Values represent the mean ( \pm SEM) of two independent DNA isolations with measurements conducted in triplicate for each isolation.

\subsection{K-SDS DNA-protein crosslinking assay}

DNA-protein crosslinks were determined using a method adapted from Zhitkovitch and Costa. ${ }^{33}$ Briefly, Jurkat cells ( 2 x $10^{5}$ cells) were treated for $1.5 \mathrm{~h}$ at $37^{\circ} \mathrm{C}$ in complete RPMI-1640 (for AZM and MC treatment) or serum-free RPMI-1640 (for 3mM formaldehyde treatment). Two different AZM and MC drug concentrations, $10 \mu \mathrm{M}$ and $100 \mu \mathrm{M}$, were used to show a concentration dependent increase in DPCs. After treatment, cells were washed twice with ice-cold PBS, resuspended in $20 \mu \mathrm{L}$ PBS, and then lysed by addition of $100 \mu \mathrm{L} 2 \%$ SDS in $20 \mathrm{mM}$ Tris-HCl solution ( $\mathrm{pH} 7.5$ ). The lysed samples were then frozen at $-20^{\circ} \mathrm{C}$. After thawing, samples were vigorously vortexed for $10 \mathrm{~s}$, warmed to $65^{\circ} \mathrm{C}$ for $10 \mathrm{~min}$ and then $100 \mu \mathrm{L}$ of a $200 \mathrm{mM} \mathrm{KCl} / 20 \mathrm{mM} \mathrm{Tris- \textrm {HCl }}$ (pH 7.5) solution was added. The DNA was sheared by passing each sample through a $200 \mu \mathrm{L}$ pipet tip five times. Samples for K-SDS precipitation were formed by chilling samples on ice for 5 min and collecting by centrifugation at $3000 \mathrm{xg}$ for $5 \mathrm{~min}$. The supernatant from each sample was saved in individual microfuge tubes and the pellets subjected to three rounds of precipitation: pellets were resuspended in $200 \mu \mathrm{L} 100 \mathrm{mM} \mathrm{KCl} / 20$ $\mathrm{mM}$ Tris-HCl (pH 7.5), heated to $65^{\circ} \mathrm{C}$ for $10 \mathrm{~min}$, placed on ice for $5 \mathrm{~min}$ and centrifuged at $3000 \mathrm{xg}$ for 5 $\mathrm{min}$. The pellets were resuspended in $0.2 \mathrm{mg} / \mathrm{mL}$ proteinase $\mathrm{K}$ solution in $100 \mathrm{mM} \mathrm{KCl} / 20 \mathrm{mM}$ Tris- $\mathrm{HCl}(\mathrm{pH}$ 7.5) and incubated at $55^{\circ} \mathrm{C}$ for $3 \mathrm{~h}$. After incubation, the samples were placed on ice for 10 min to allow the precipitation of SDS. Samples were centrifuged at 10,000 $\mathrm{g}$ for $10 \mathrm{~min}$ and the supernatants collected. The quantity of protein-linked and non-linked DNA was measured using SYBR Green dye (Invitrogen, Carlsbad, CA) and comparing fluorescence values against a known DNA standard. The percent DPC was calculated as \% DPC = [protein-linked DNA/(non-linked DNA + protein-linked DNA)] x 100\%.

\section{Supplementary data}

Supplementary data (representative resazurin antiproliferative activity profiles, HPLC chromatograms obtained as part of decomposition studies, and representative fluorescent images of anaerobic Jurkat cells following the modified alkaline COMET assay and SYBR green staining) associated with this article can be found, in the online version, at http://dx.doi.org.....

\section{Acknowledgments}

The work described in this paper was supported in part by funding from NIH/NCI (R15CA113464), an Institutional Development Award (IDeA) from the NIH/NIGMS (P20GM103408), the BSU COBRE in Matrix Biology (NIH P20 GM109095), and the Idaho Global Entrepreneurial Mission University Infrastructure program. Its contents are solely the responsibility of the authors and do not necessarily represent the official views of the NIH or the State of Idaho.

\section{References}

1. Hata, T.; Sano, Y.; Sugawara, R.; Matsumae, A.; Kanamori, K.; Shima, T.; Hoshi, T. I. J. Antibiot.; Ser. A. 1956, 9, 141.

2. Bradner, W. T. Cancer Treat. Rev. 2001, 27, 35.

3. Ross, D.; Beall, H.; Traver, R. D.; Siegel, D.; Phillips, R. M.; Gibson, N. W. Oncol. Res. 1994, 6, 493.

4. Siegel, D.; Gibson, N. W.; Preusch, P. C.; Ross, D. Cancer Res. 1990, 50, 7483.

5. Pan, S.-S.; Andrews, P. A.; Glover, C. J.; Bachur, N. R. J. Biol. Chem. 1984, 259, 959 
6. Cummings, J.; Spanswick, V. J.; Tomasz, M.; Smyth, J. F. Biochem. Pharmacol. 1998, 56, 405.

7. Kumar, G. S.; Lipman, R.; Cummings, J.; Tomasz, M. Biochemistry 1997, 36, 14128.

8. Iyer, V. N.; Szybalski, W. Proc. Natl. Acad. Sci. U.S.A. 1963, 50, 335.

9. Tomasz, M.; Palom, Y. Pharmacol. Ther. 1997, 76, 73.

10. Schiltz, P.; Kohn, H. J. Am. Chem. Soc. 1993, 115, 10510.

11. Peterson, D. M.; Fisher, J. Biochemistry 1986, 25, 4077.

12. Han, I.; Kohn, H. J. Org. Chem. 1991, 56, 4648.

13. Norman, D.; Live, D.; Sastry, M.; Lipman, R.; Hingerty, B. E.; Tomasz, M.; Broyde, S.; Patel, D. Biochemistry 1990, 29, 2861.

14. Sastry, M.; Fiala, R.; Lipman, R.; Tomasz, M.; Patel, D. J. J. Mol. Biol. 1995, 247, 338.

15. Li, V.-S.; Choi, D.; Wang, Z.; Jimenez, L. S.; Tang, M.; Kohn, H. J. Am. Chem. Soc. 1996, 118, 2326.

16. Rink, S. M.; Warner, D. L.; Klapars, A.; Vedejs, E. Biochemistry 2005, 44, 13981.

17. Vedejs, E.; Naidu, B. N.; Klapars, A.; Warner, D. L.; Li, V.-s.; Na, Y.; Kohn, H. J. Am. Chem. Soc. 2003, 125, 15796.

18. Coulombe, R. A.; Drew, G. L.; Stermitz, F. R. Toxicol. Appl. Pharm. 1999, 154, 198.

19. Kim, H. Y.; Stermitz, F. R.; Coulombe, R. A. Carcinogenesis 1995, 16, 2691.

20. Dorr, R. T.; Bowden, T.; Alberts, D. S.; Liddil, J. D. Cancer Res. 1985, 45, 3510.

21. O’Brien, J.; Wilson, I.; Orton, T.; Pognan, F. Eur. J. Biochem. 2000, 267, 5421.

22. Hamid, R.; Rotshteyn, Y.; Rabadi, L.; Parikh, R.; Bullock, R. Toxicol. In Vitro 2004, 18, 703.

23. Fracasso P. M.; Sartorelli, A. C. Cancer Res. 1986, 46, 3939.

24. Pfuhler, S.; Wolf, H. U. Environ. Mol. Mutagen. 1996, 27, 196.

25. Merk, O.; Speit, G. Environ. Mol. Mutagen. 1999, 33, 167.

26. McKenna, D. J.; Gallus, M.; McKeown, S. R.; Downes, C. S.; McKelvey-Martin, V. J. DNA Repair 2003, 2 , 879.

27. Alotaibi, A.; Baumgartner, A.; Najafzadeh, M.; Cemeli, E.; Anderson, D. J. Cancer Ther. 2012, 3, 78.

28. Volpato, M.; Seargent, J.; Loadman, P. M.; Phillips, R. M. Eur. J. Cancer, 2005, 41, 1331.

29. Penketh, P. G.; Shyam, K.; Sartorelli, A. C. Anal. Biochem. 1997, 252, 210.

30. Penketh, P. G.; Hodnick, W. F.; Belcourt, M. F.; Shyam, K.; Sherman, D. H.; Sartorelli, A. C. J. Biol. Chem. 2001, 276, 34445.

31. Palom, Y.; Kumar, G. S.; Tang, L.-Q.; Paz, M. M.; Musser, S. M.; Rockwell, S.; Tomasz, M. Chem. Res. Toxicol. 2002, 15, 1398.

32. Hincks, J. R.; Coulombe, R. A. Environ. Mol. Mutagen. 1989, 13, 211.

33. Zhitkovich, A.; Costa, M. Carcinogenesis 1992, 13, 1485.

34. When Me-AZM and H-AZM were subjected to experiments with synthetic oligonucleotides using conditions analogous to those described in reference 16, H-AZM gave DNA ICL in $0.30 \%$ yield after $16 \mathrm{~h}$, while Me-AZM produced only $0.03 \%$.

35. Lown, J. W.; Begleiter, A.; Johnson, D.; Morgan, A. R. Can. J. Biochem. 1976, 54, 110.

36. Paz, M. M.; Das, A.; Palom, Y.; He, Q.-Y.; Tomasz, M. J. Med. Chem. 2001, 44, 2834.

37. Paz, M. M.; Tomasz, M. Org. Lett. 2001, 3, 2789.

38. Vedejs, E.; Klapars, A.; Naidu, B. N.; Piotrowski, D. W.; Tucci, F. C. J. Am. Chem. Soc. 2000, $122,5401$.

39. Wang, Y., Gray, J. P., Mishin, V.; Heck, D. E.; Laskin, D. L.; Laskin, J. D. Mol Cancer Ther. $2010,9,1852$.

40. Rasband, W.S., ImageJ, U. S. National Institutes of Health, Bethesda, Maryland, USA, http://imagej.nih.gov/ij/, 1997.

41. Gyori, B. M.; Venkatachalam, G.; Thiagarajan, P. S.; Hsu, D.; Clement, M.-V. Redox Biology 2014, 2, 457. 